\title{
Heart Undifferentiated Pleomorphic
} Sarcoma

National Cancer Institute

\section{Source}

National Cancer Institute. Heart Undifferentiated Pleomorphic Sarcoma. NCI Thesaurus. Code C45755.

An undifferentiated pleomorphic sarcoma usually arising from the left atrium of the heart. It is characterized by the presence of fibrohistiocytic cells, giant cells, and spindle cells arrranged iin a storiform pattern. Clinical presentation includes signs and symptoms associated with left atrial hemodynamic changes. 